\title{
PENGARUH PENERAPAN STRATEGI PEMBELAJARAN THE POWER OF TWO TERHADAP KEMAMPUAN MENULIS RESENSI
}

\author{
Eti Ramaniyar', Khairumi Rosanti ${ }^{2}$ \\ ${ }^{1}$ Program StudiPendidikan Bahasa dan Sastra Indonesia, \\ Fakultas Pendidikan Bahasa dan Seni, IKIP PGRI Pontianak \\ ${ }^{1}$ Eramaniyar25@gmail.com
}

\begin{abstract}
Abstrak
Penelitian ini bertujuan untuk mengetahui "Pengaruh penerapan strategi pembelajaran the power of two terhadap kemampuan menulis resensi pada siswa kelas XI SMA Negeri 1 Sungai Ambawang". Metode pada penelitian ini menggunakan metode eksperimen, bentuk penelitiannya adalah pre-experimental design, rancangan penelitian yang digunakan adalah penelitian one group pretest posttest design. Hasil penelitian menunjukkan terdapat pengaruh penerapan strategi pembelajaran the power of two terhadap kemampuan menulis resensi pada siswa kelas XI MIPA 4 SMA Negeri 1 Sungai Ambawang yaitu sebelum menerapkan strategi pembelajaran the power of two siswa memperoleh nilai rata-rata sebesar 61,83. Sedangkan setelah menerapkan strategi pembelajaran the power of two siswa memperoleh nilai rata-rata sebesar 75,58.
\end{abstract}

Kata Kunci : strategi pembelajaran, the power of two, menulis

\begin{abstract}
This study aims to determine "The Effectiveness of the Implementation the power of two learning strategies on writing ability recession at the eleventh grade students of SMA Negeri 1 Sungai Ambawang". The method in this study used the experimental method, the form of the study was pre-experimental design, the research design used was the research of one group pretest posttest design. The results showed that there was an Effectiveness of the Implementation the power of two learning strategies on writing ability recession at the eleventh grade students of SMA Negeri 1 Sungai Ambawang namely before applying the learning strategy the power of two students obtained an average score of 61.83. Whereas after applying the learning strategy the power of two students obtain an average score of 75.58 .
\end{abstract}

Keywords: learning strategies, the power of two, writing

\section{PENDAHULUAN}

Keterampilan berbahasa mempunyai empat aspek yaitu, keterampilan menyimak, keterampilan berbicara, keterampilan membaca, dan keterampilan menulis. Keterampilan menulis merupakan salah satu aspek dalam keterampilan berbahasa. Menulis merupakan suatu keterampilan berbahasa yang harus dikuasai oleh siswa, karena menulis memerlukan pengetahuan khusus. Menulis adalah keterampilan 
yang sifatnya produktif, yaitu suatu bentuk kegiatan yang menghasilkan tulisan.Pembelajaran menulis yang dilaksanakan di lembaga pendidikan formal merupakan satu diantara bagian dari materi pembelajaran bahasa Indonesia. Pembelajaran menulis sangat penting dalam pendidikan karena memudahkan para pelajar berpikir, melaporkan atau memberitahukan, dan mempengaruhi.

Pembelajaran menulis resensi pada siswa kelas XI SMA Negeri I Sungai Ambawang tentunya juga memerlukan pemahaman yang mendalam, misalnya dalam hal mencapai pemahaman menulis resensi, penggunaan model pembelajaran atau strategi pembelajaran sangat diperlukan. Berdasarkan observasi yang peneliti lakukan, guru pada mata pelajaran bahasa Indonesia jarang bahkan tidak pernah menggunakan strategi pembelajaran the power of two. Strategi yang diterapkan masih menggunakan strategi lama, yaitu ceramah dan terkadang hanya Tanya jawab. Sehingga pembelajaran terasa atau terkesan membosankan karena proses pembelajaran yang satu arah seperti itu.

Harapan peneliti dari penelitian ini adalah dengan diterapkannya strategi pembelajaran the power of two akan memberikan nuansa baru bagi siswa, hal ini menyebabkan siswa lebih aktif dan termotivasi lagi untuk melakukan proses pembelajaraan di kelas dan dapat mencapai tujuan pembelajaran secara optimal sehingga tujuan yang dirumuskan dapat tercapai serta dapat memberikan pengaruh yang baik pada pembelajaran menulis, khususnya menulis resensi. Berdasarkan uraian di atas, inilah yang mendorong peneliti untuk melakukan penelitian dengan mengangkat judul "Pengaruh Penerapan Strategi Pembelajaran The Power Of Two Terhadap Kemampuan Menulis Resensi Pada Siswa Kelas XI SMA Negeri 1 Sungai Ambawang".

StrategipembelajaranmenurutSuprijono (2017:1) merupakan kegiatan yang dipilih yang dapat memberikan fasilitas atau bantuan kepada peserta didik untuk mencapai tujuan pembelajaran. Menurut David (Asih, 2016:2) "strategi pembelajaran adalah perencanaan yang berisi tentang rangkaian kegiatan yang didesain untuk mencapai tujuan pendidikan tertentu". Berdasarkan uraian di atas dapat disimpulkan bahwa strategi pembelajaran adalah upaya yang dilakukan oleh seseorang untuk sampai pada tujuan tertentu, dan suatu tindakan dari guru atau 309 
prosedur yang digunakan untuk memberikan suasana yang konduktif kepada siswa dalam rangka mencapai tujuan pembelajaran, serta kegiatan yang dipilih dan dapat memberikan fasilitas atau bantuan kepada peserta didik untuk mencapai tujuan pembelajaran.

The Power Of Two (kekuatan dua kepala) merupakan strategi pembelajaran untuk mendorong pembelajaran kooperatif dan memperkuat arti penting serta manfaat sinergi dua orang" Zaini, (Sufanti, 2010:56). Strategi ini mempunyai prinsip bahwa berpikir berdua jauh lebih baik daripada berpikir sendiri. Menurut Silberman (2016:173) the power of two berarti menggabungkan kekuatan dua kepala. Menggabungkan dalam hal ini adalah membentuk kelompok kecil, yaitu masing-masing siswa berpasangan. Kegiatan ini dilakukan agar munculnya suatu sinergi yakni dua kepala lebih baik dari pada satu.

Berdasarkan uraian di atas dapat disimpulkan bahwa strategi pembelajaran the power of two artinya menggabung kekuatan dua orang. Menggabungkan kekuatan dua orang dalam hal ini adalah membentuk kelompok kecil, masingmasing kelompok terdiri dari dua. Strategi pembelajaran the power of two ini diketahui sebagai strategi yang efektif diterapkan, karena menekankan pada proses mencari dan menemukan secara interaktif. Pembelajaran dengan strategi the power of two ini juga menuntut siswa agar lebih aktif dalam proses belajar mengajar sehingga siswa tidak merasa bosan, karena pembelajaran lebih menarik dan menuntut partisipasi siswa terhadap materi pelajaran.

Dalman, (2016:3) menyatakan bahwa "menulis merupakan sebuah proses kreatif menuangkan gagasan dalam bentuk bahasa tulis dalam tujuan, misalnya memberitahu, meyakinkan, atau menghibur”. Menurut Tarigan (2008 : 3) menyatakan bahwa "menulis merupakan suatu keterampilan berbahasa yang dipergunakan untuk berkomunikasi secara tidak langsung, tidak secara tatap muka dengan orang lain". Berdasarkan pendapat para ahli di atas dapat disimpulkan bahwa menulis adalah proses penyampaian pikiran, angan-angan, perasaan dalam bentuk lambang/tanda/tulisan yang bermakna.Menulis merupakan suatu bentuk berfikir yang dituangkan dalam kata-kata yang lebih mudah dipahami dan mudah dimengerti untuk berbagai tujuan dalam bentuk tulisan 
Menulis termasuk kegiatan yang kompleks karena penulis dituntut untuk dapat menyusun dan mengorganisasikan isi tulisannya serta menuangkannya dalam formulasi bahasa tulis dan dalam penulisan-penulisan lainnya, satu diantaranya ialah menulis resensi. Resensi merupakan satu diantara tulisan jurnalistik yang bertujuan untuk mendeskripsikan dan memberikan pertimbangan kepada pembaca mengenai sebuah buku yang baru diterbitkan. Alasan penulis memilih materi menulis resensi karenamenulis resensi memerlukan pengetahuan khusus, menulis resensi merupakan materi yang cukup sulit dikuasai oleh siswa. Adapun alasan lainnya yaitudi sekolah materi menulis sebagai satu diantara keterampilan berbahasa Indonesia yang kurang mendapat perhatian oleh guru, sehingga pembelajaran menulis menjadi membosankan.Selainitu, dalam mengajar guru masih terkesan teoritis dalam menyampaikan materi, pada saat guru mengajar yang digunakan hanyalah metode konvensional misalnya metode ceramah atau penugasan.

Resensi menurut Dalman (2016:229) adalah sebuah istilah yang digunakan untuk menilai baik tidaknya sebuah buku". Resensi merupakan salah satu bentuk tulisan jurnalistik yang bertujuan untuk mendeskripsikan dan memberi pertimbangan kepada pembaca mengenai sebuah buku yang baru diterbitkan. Secara sederhana, resensi dapat dianggap sebagai bentuk tulisan yang merupakan perpaduan antara ringkasan dan ikhtisar berisi penilaian, ringkasan isi buku, pembahasan, atau kritik terhadap buku tersebut. Bentuk tulisan ini bergerak di subyektivitas peresensinya dengan bekal pengetahuan yang dimilikinya tentang bidang itu. Resensi memiliki bagian-bagian penting di dalamnya, diantaranya judul resensi, identitas buku, bagian pembuka resensi yang memaparkan kepengarangan, tema, golongan buku, isi atau tubuh resensi yang memaparkan ikhtisar, ulasan serta kutipan, dan kelemahan juga kelebihan buku, dan bagian penutup.

Senada dengan pendapat di atas Keraf (2002:274) menyatakan bahwa resensi adalah suatu tulisan atau ulasan mengenai nilai sebuah hasil karya atau buku. Sejalan dengan pendapat Keraf, menurut Widjono resensi adalah ulasan atau penilaian sebuah hasil karya, buku, fil, produk teknologi, dan lain-lain. Penilaian ini menyajikan kualitas sebuah karya, baik yang berhubungan dengan kualitas yang 311 
terkait dengan keunggulan maupun kekurangan-kekurangannya. Menurut beberapa pendapat di atas dapat disimpulkan bahwa resensi adalah tulisan ilmiah yang membahas isi sebuah buku, termasuk kelemahan dan keunggulannya untuk diberitahukan kepada pembaca apakah sebuah buku atau hasil karya itu patut mendapat sambutan baik dari masyarakat atau tidak.

\section{METODE PENELITIAN}

Metode penelitian yang digunakan dalam penelitian ini adalah metode eksperimen.Rancangan yang digunakan dalam penelitian ini adalah One Group Pretest-Posttest Design, yakni sekelompok objek yang dikenai perlakuan untuk jangka waktu tertentu dan kemudian diobservasi hasilnya. Hasil perlakuan didapat lebih akurat karena dapat membandingkan dengan keadaan sebelum diberikan perlakuan.populasi dalam penelitian ini adalah siswa kelas XI SMA Negeri 1 Sungai Ambawang yang terdiri dari enam kelas. sampel dalam penelitian ini dengan cara simple random sampling, alasan memilih simple random sampling karena jumlah populasi dalam penelitian ini tidak terlalu besar dan pengambilan sampel tanpa memperhatikan strata dilakukan secara acak dengan menggunakan lintingan kertas seperti yang biasa dilakukan dalam kegiatan arisan. Adapun kelas yang menjadi sampel dalam penelitian ini adalah kelas XI MIPA 4 dengan jumlah sampel 30 siswa.

Teknik pengumpulan data yang digunakan dalam penelitian ini yaitu menggunakan teknik pengukuran dan teknik studi dokumenter. Sedangkan alat pengumpul data yang digunakan yaitu essay dan dokumentasi. Teknik analisis data yang digunakan dalam penelitian ini yaitu :

1. Untuk menjawab sub masalah 1 dan 2 menggunakan rumus mean (Zuldafrial, 2012:117) adalah :

$$
\mathrm{X}=\frac{\sum X}{N}
$$

Katerangan:

$$
\begin{array}{ll}
\mathrm{X} & =\text { Mean (rata-rata) } \\
\sum X & =\text { Jumlah skor }
\end{array}
$$




$$
\mathrm{N} \quad=\text { Jumlah sampel }
$$

2. Mencari mean guna mencari skor penyimpangan

1) Mencari mean variabel 1 (variabel $X)$, dengan rumus :

$$
\text { MX atau M1 }=\frac{\sum X}{N 1}
$$

2) Mencari mean variabel 2 (variabel $Y$ ), dengan rumus :

$$
\mathrm{MY} \text { atau } \mathrm{M} 2=\frac{\sum \mathrm{X}}{\mathrm{N} 2}
$$

Keterangan :

$$
\begin{array}{ll}
\text { MX atau M1 } & \text { = rata-rata hitung yang akan dicari (variabel } \\
& \text { X/ variabel1) } \\
\text { MY atau M2 } & =\text { rata-rata hitung yang akan dicari (variabel } \\
& \text { Y/ variabel2) } \\
\sum \mathrm{X} & =\text { Jumlah skor } \\
\mathrm{N} 1 & =\text { Jumlah subjek (variabel X/ variabel1) } \\
\mathrm{N} 2 & =\text { Jumlah subjek (variabel Y/ variabel2) }
\end{array}
$$

Zuldafrial (2012:137)

Kriteria nilai rata-rata (mean) adalah sebagai berikut:

$82-100=$ Tergolong Sangat Tinggi

$63-82=$ Tergolong Tinggi

$44-63=$ Tergolong Sedang

$25-44$ =Tergolong Rendah

3. Tes "T"

Untuk menjawab sub masalah 3 adalah dengan menggunakan rumus tes " $t$ " dengan rumus:

$$
\text { to }=\frac{\mathrm{MD}}{S E_{M D}}
$$

MD = Mean of Diffrences $=$ nilai rata-rata hitung dari beda/selisih antar skor variabel I dan skor variabel II, yang dapat diperoleh dengan rumus: 


$$
\mathrm{MD}=\Sigma \frac{\mathrm{D}}{\mathrm{N}}
$$

$\sum \mathrm{D}=$ Jumlah beda/selisih antara skor variabel I (variabel $\mathrm{X}$ ) dan skor variabel II (variabel Y) dan D dapat diperoleh dengan rumus:

$$
\mathrm{D}=\mathrm{X}-\mathrm{Y}
$$

$\mathrm{N}=$ Number of cases $=$ jumlah subjek yang kita teliti

$\mathrm{SE}_{\mathrm{MD}}=$ Standar error (standar kesesatan) dari Mean of Diffrences yang dapat diperoleh dengan rumus:

$$
\mathrm{SE}_{\mathrm{MD}}=\frac{\mathrm{SD}_{\mathrm{D}}}{\sqrt{\mathrm{N}-1}}
$$

$\mathrm{SD}_{\mathrm{D}} \quad=$ Deviasi standar dari perbedaan antara skor variabel I dengan skor variabel II yang dapat diperoleh dengan rumus:

$$
\mathrm{SD}_{\mathrm{D}}=\sqrt{\sum \frac{\mathrm{D}^{2}}{\mathrm{~N}}-\frac{\left(\sum-\mathrm{D}\right)^{2}}{\mathrm{~N}}}
$$

Zuldafrial (2012:131)

\section{Effect Size}

Untuk menjawab rumusan masalah 4 dengan menggunakan rumus effect size yaitu:

$$
\mathrm{ES}=\frac{X_{e}-X_{k}}{S_{c}}
$$

Adapun kriteria penilaian indek diterminasi besarnya pengaruh mengacu pada pendapat Sugiyono, (2015:63) yaitu:

1) $0,80-1,00$ artinya pengaruh yang kuat sekali

2) $0,60-0,799$ artinya pengaruh kuat

3) $0,40-0,599$ artinya pengaruh yang cukup

4) $0,20-0,399$ artinya pengaruh lemah

0,000-0,199 artinya pengaruh sangat lemah 


\section{HASIL PENELITIAN DAN PEMBAHASAN}

Hasil penelitian yang telah diperoleh peneliti selama melaksanakan proses penelitian di SMA Negeri 1 Sungai Ambawang. Data pretest dan posttest digunakan untuk mengetahui kemampuan awal dan akhir siswa pada kelas eksperimen. Data pretest dan posttest terdiri dari 30 siswa. Skor yang diberikan memiliki rentang tertentu sesuai dengan format penilaian kemampuan menulis resensi. Dari hasil pengolahan data pretest dan posttest terlihat sebagai berikut.

\section{Rata-rata Hasil Kemampuan Menulis Resensi.}

Berdasarkan sub masalah 1 dan 2 mengenai kemampuan menulis resensi siswa kelas XI SMA Negeri 1 Sungai Ambawang berupa tes, dapat dijawab dengan menggunakan rumus rata-rata (mean) dengan rata-rata nilainya sebagai berikut.

a. Sebelum penerapan strategi pembelajaran The Power Of Two (Pretest):

Rata-rata (Mean)

$\mathrm{X}=\frac{\Sigma X}{n}=\frac{1855}{30}=61,83$

b. Setelah penerapan strategi pembelajaran The Power Of Two (Posttest):

Rata-rata (Mean)

$\mathrm{X}=\frac{\Sigma X}{n}=\frac{2267,5}{30}=75,58$

Dari hasil tersebut dapat dideskripsikan bahwa kedua tes tersebut memiliki perbandingan. Pada pretest rata-rata hasil belajar siswa belum mencapai KKM yaitu 61,83, sedangkan pada posttest rata-rata hasil belajar siswa 75,58 di atas rata-rata nilai KKM bahasa Indonesia.

\section{Besarnya Pengaruh}

Dari perhitungan yang diperoleh $t_{\text {tabel }}<t_{\text {hitung }}>t_{\text {tabel }}$ yaitu 2,04 $<7,51>2,75$ maka dapat disimpulkan bahwa H0 ditolak dan Ha diterima dengan kesimpulan terdapat pengaruh penerapan strategi pembelajaran The Power Of Two terhadap kemampuan menulis resensi pada siswa kelas XI SMA Negeri 1 Sungai Ambawang. 


\section{Mengukur Pengaruh}

Dalam mengukur pengaruh menggunakan rumus Effect Size sebagai berikut:

$$
\mathrm{ES}=\frac{X_{e}-X_{k}}{S_{c}}=\frac{75,60-61,83}{10,95}=\frac{13,77}{10,95}=1,25
$$

\section{SIMPULAN}

Berdasarkan hasil penelitian dan analisis data yang dilakukan untuk menjawab masalah penelitian, secara umum diketahui bahwa terdapat pengaruh strategi pembelajaran the power of two terhadap kemampuan menulis resensi pada siswa kelas XI MIPA 4 SMA Negeri 1 Sungai Ambawang. Pengaruh strategi pembelajaran the power of two terhadap kemampuan menulis resensi pada siswa kelas XI MIPA 4 SMA Negeri 1 Sungai Ambawang tahun pelajaran 2018/2019 termasuk dalam kategori tinggi dengan hasil effect size sebesar 1,25. Adapun hasil yang diperoleh akan dijabarkan sebagai berikut:

1. Kemampuanmenulisresensi dikelasXI MIPA 4 SMA Negeri 1 Sungai Ambawang sebelum menerapkan strategi pembelajaran the power of two memperoleh nilai rata-rata sebesar 61,83 .

2. Kemampuan menulis resensi di kelas XI MIPA 4 SMA Negeri 1 Sungai Ambawang setelah menerapkan strategi pembelajaran the power of two memperoleh nilai rata-rata sebesar 75,58.

3. Terdapat pengaruh penerapan strategi pembelajaran the power of two terhadap kemampuan menulis resensi pada siswa kelas XI MIPA 4 SMA Negeri 1 Sungai Ambawang.

4. Berdasarkan perhitungan dan kriteria besarannya Effect Size dapat disimpulkan bahwa besarnya pengaruh kemampuan menulis resensi pada siswa kelas XI MIPA 4 SMA Negeri 1 Sungai Ambawang yaitu sebesar 1,25.

\section{DAFTAR PUSTAKA}

Asih. (2016). Strategi Pembelajaran Bahasa Indonesia. Bandung: CV Pustaka Setia.

Dalman. (2016). Keterampilan Menulis. Jakarta: PT Raja Grafindo Persada. 
Keraf. (2002). Komposisi Sebuah Pengantar Kemahiran Bahasa. Flores: Nusa Indah.

Silberman. (2016). Active Learning 101 Cara Belajar Siswa Aktif. Bandung:Penerbit Nuansa Cendekia.

Sufanti. (2010). Strategi Pengajaran Bahasa dan Sastra Indonesia. Surakarta: Yuma Pustaka

Suprijono. (2017). Cooperative Learning TEORI DAN APLIKASI PAIKEM. Yogyakarta: Pustaka Pelajar.

Tarigan. (2008). Menulis Sebagai Suatu Keterampilan Berbahasa. Bandung: Angkasa.

Zuldafrial. (2012). Penelitian Kuantitatif. Yogyakarta: Media Perkasa. 